

http://www.diva-portal.org

This is the published version of a paper published in Bilingualism: Language and Cognition.

Citation for the original published paper (version of record):

Kormi-Nouri, R., Moradi, A., Moradi, S., Akbari-Zardkhaneh, S., Zahedian, H. (2012)

The effect of bilingualism on letter and category fluency tasks in primary school children: advantage or disadvantage?

Bilingualism: Language and Cognition, 15(2): 351-364

http://dx.doi.org/10.1017/S1366728910000192

Access to the published version may require subscription.

N.B. When citing this work, cite the original published paper.

Permanent link to this version:

http://urn.kb.se/resolve?urn=urn:nbn:se:oru:diva-1347 1 
Bilingualism: Language and Cognition

http://journals.cambridge.org/BIL

Additional services for Bilingualism: Language and Cognition:

Email alerts: $\underline{\text { Click here }}$

Subscriptions: $\underline{\text { Click here }}$

Commercial reprints: $\underline{\text { Click here }}$

Terms of use : $\underline{\text { Click here }}$

\title{
The effect of bilingualism on letter and category fluency tasks in primary school children: Advantage or disadvantage?
}

\author{
REZA KORMI-NOURI, ALI-REZA MORADI, SHAHRAM MORADI, SAEED AKBARI-ZARDKHANEH and HAEDEH
} ZAHEDIAN

Bilingualism: Language and Cognition / Volume 15 / Issue 02 / April 2012, pp 351 - 364

DOI: 10.1017/S1366728910000192, Published online: 06 October 2010

Link to this article: http://journals.cambridge.org/abstract_S1366728910000192

How to cite this article:

REZA KORMI-NOURI, ALI-REZA MORADI, SHAHRAM MORADI, SAEED AKBARI-ZARDKHANEH and HAEDEH ZAHEDIAN (2012). The effect of bilingualism on letter and category fluency tasks in primary school children: Advantage or disadvantage?. Bilingualism: Language and Cognition, 15, pp 351-364 doi:10.1017/S1366728910000192

Request Permissions : $\underline{\text { Click here }}$ 


\title{
The effect of bilingualism on letter and category fluency tasks in primary school children: Advantage or disadvantage?*
}

\author{
REZA KORMI-NOURI \\ Center for Health \& Medical Psychology, Örebro \\ University, Sweden \& Department of Psychology, \\ University of Tehran, Iran \\ A L I-REZA MORADI \\ Department of Psychology, Tehran Teacher Training \\ University, Iran \\ SHAHRAM MORADI \\ Center for Health \& Medical Psychology, Örebro \\ University, Sweden \\ SAEED AKBARI-ZARDKHANEH \\ Allameh Tabatabaei University, Tehran, Iran \\ HAEDEH ZAHEDIAN \\ Azad University, Tehran, Iran
}

(Received: November 6, 2008; final revision received: February 21, 2009; accepted: March 19, 2010; first published online October 6, 2010)

The aim of the current study was to examine the effects of bilingualism on letter and category fluency tasks. Participants were 1,600 monolingual and bilingual children from three cities in Iran: Tehran (Persian monolinguals), Tabriz (Turkish-Persian bilinguals), and Sanandaj (Kurdish-Persian bilinguals). We separately presented nine Persian letters and thirty-one categories to the participants, and asked them to generate as many words as possible using each of these initial letters and categories within a maximum of three minutes. Bilingual children generated more words than monolingual children in the letter fluency task; this effect was more pronounced in Grade 1 and for Turkish-Persian bilinguals. However, Persian monolinguals generated significantly more words than both bilingual groups in the category fluency task. Thus, bilingualism can be of both advantage and disadvantage, and produce a dissociative effect. We discuss the results on the basis of the specific nature and different cognitive demands of letter and category fluency tasks. We suggest that the degree of language proficiency of bilinguals should be considered as an important variable in future research on bilingualism.

Keywords: bilingualism, letter fluency task, category fluency task, primary school children

Research into the effects of bilingualism on cognitive development began in the 19th century in the context of IQ testing. Most of the earlier studies suggested that bilingualism was associated with negative consequences in intelligence (e.g., Anastasi \& Cordova, 1953; Darcy, 1953). These studies supported the ideas that bilingual children suffer from academic retardation and are socially maladjusted as compared with monolingual children (Hamers \& Blanc, 2000). This traditional view was expanded to encompass the claim that bilingualism has a negative effect on cognitive development (e.g., Mägiste,

\footnotetext{
* This study was part of a project entitled "The study of cognitive aspects of reading and dyslexia in bilingual and monolingual children", approved and supported by research councils at the University of Tehran and the Ministry of Education in Iran. We would like to thank these two research organizations, all children who participated and all parents and teachers who helped and supported us in this study. Thanks also to Ali-Reza Gholami and Shima Nabifar for their valuable efforts during the data collection. We are also very grateful to anonymous reviewers for their valuable comments on an earlier draft of the manuscript.
}

1979). The findings of these studies support the crosslanguage interference hypothesis, which assumes that bilinguals are unable to turn one language off when the other language is used, whereas monolinguals do not face any competition between two languages or any subsequent interference (e.g., Gollan, Montoya \& Werner, 2002).

By contrast, some other studies have shown that bilingualism has a positive effect on children's cognitive development (e.g., Bialystok, 1999; Kormi-Nouri, Moniri \& Nilsson, 2003; Oren, 1981). Their findings support the bilingual advantage hypothesis, which postulates that bilingual children have extensive practical experience of two languages at an early age and become more able than their monolingual counterparts to focus on parts of a body of information and inhibit other parts. There is also a suggestion that bilingual advantages depend on the complexity of tasks and level of cognitive demands (Bialystok, 2001, 2004, 2005).

Testing verbal fluency is useful in evaluating executive function and language. In verbal fluency tasks, participants are asked to generate as many words as

Address for correspondence:

Reza Kormi-Nouri, Center for Health \& Medical Psychology (CHAMP), Örebro University, 70182 Örebro, Sweden

reza.kormi-nouri@oru.se 
possible that conform to a constraint given by an initial letter (e.g., "F") or category membership (e.g., "animals") during a fixed period of time (Strauss, Sherman \& Spreen, 2006). Estes (1974) suggested that verbal fluency tasks present excellent information on how people organize their thinking. Also, he pointed out that successful performance on such tasks depends somewhat on the subject's ability to organize output in terms of clusters of meaningfully related words. Verbal fluency tasks provide useful information about the development of both wordretrieval strategies and lexical-semantic networks during childhood (Sauzéon et al., 2004). Verbal fluency tasks are normally used as neuropsychological measures of cognitive functioning, and performance can be interpreted diagnostically to indicate changes in cognitive function with age, and also abnormal patterns of cognitive behavior (Bialystok, Craik, Luk, 2008a). Verbal fluency tasks constitute one of the most commonly used tests in neuropsychological evaluations, perhaps because they are both sensitive to a broad variety of disorders and relatively quick and easy to administer (Gollan et al., 2002).

There are only a few studies of verbal fluency in bilinguals and monolinguals. Adult studies have produced mixed results with regard to bilinguals' performance in verbal fluency tasks. Gollan et al. (2002) reported that bilinguals perform less well than monolinguals in both letter and category fluency tasks. They found a significant interaction between the two, such that bilingual disadvantage was greater for semantic fluency than it was for letter fluency. To explain the interaction, they suggested that interference between languages is likely to be greater for semantic fluency, where translation equivalents are category members, whereas for letter fluency, if translations come to mind, they can usually be rejected immediately because they do not begin with the same letter. Portocarrero, Burright and Donovick (2007) and Rosselli et al. (2000) found that bilinguals performed less well in category fluency relative to monolinguals, but there was no difference between monolinguals and bilinguals in letter fluency. Thus, the findings of Portocarrero et al. (2007) and Rosselli et al. (2000) are in line with those of Gollan et al.'s (2002) study with regard to category fluency, but they failed to find a difference between the groups on letter fluency. Rosselli et al. (2000) proposed that the differential nature of the tasks may cause such dissociation. Category fluency usually correlates with lexical knowledge, whereas letter fluency correlates more with executive function. A similar explanation was put forward by Hurks et al. (2004), who found that children suffering from attention deficit hyperactivity disorder (ADHD) performed less well than controls on letter fluency tasks, but there was no difference between the groups on category fluency tasks. A possible explanation for this finding is that category tasks may rely more on access to lexical representations of semantic concepts, whereas letter tasks may rely more on the central executive component of working memory (Marczinski \& Kertesz, 2006). Neuroimaging data also show that, although there are overlapping brain regions for activation during letter and category fluency tasks, there are dissociable brain areas as well (e.g., Gourovitch et al., 2000; Jurado et al., 2000).

Another explanation, suggested by Rosselli et al. (2002), was that category fluency solely involves the recall of concrete words, whereas letter fluency does not. Concrete words may share more elements of their representations across two languages and promote more language interference. This is why, it is claimed, category fluency tasks become more difficult than letter fluency tasks for bilinguals than for monolinguals. Furthermore, Portocarrero et al. (2007) proposed that culture may give rise to these differences, since bilingual and monolingual children have different cultural backgrounds. For example, some groups in America with their own culture have fewer items to use in some categories (e.g., kitchen utensils) than those with a pure American culture; thus, bilinguals generate fewer words than do monolinguals.

To our knowledge, there are only two studies that have investigated performance on verbal fluency tasks among bilingual and monolingual children. Kormi-Nouri et al. (2003) reported that bilinguals performed better than monolinguals on a letter fluency test. The bilingual advantage was more pronounced for older than for younger children. Also, Kormi-Nouri et al. (2008), reporting on four experiments (by using different letters), found a bilingual advantage in two of their experiments (Experiments 3 and 4) on both letter and category fluency tasks. A mixed result of bilingual advantages was found for younger children (primary school) compared to older (high school) children: Whereas, in two experiments (1 and 2) bilingual advantages were more pronounced for younger children than for older children, in the other two experiments ( 3 and 4 ) the opposite held true. They also found no difference between bilinguals and monolinguals (in Experiment1), and even a bilingual disadvantage (in Experiment 2). In this study, the mixed results could be possibly due to the use of different exemplar and number of letters and differences in letter difficulty and word frequency for each letter (Borkowski, Benton \& Spreen, 1967).

From existing research, therefore, we cannot draw any clear conclusion whether childhood bilingualism is of advantage or disadvantage in verbal fluency tasks in general, or in either letter or category fluency task in particular. The main purpose of the research presented here was to study more widely and systematically letter and category fluency tasks in a normal population of both bilingual and monolingual children. Our two previous 
studies had some limitations and demonstrated mixed results. The first study (Kormi-Nouri et al., 2003) reported an advantage for bilinguals solely in a letter fluency task; category fluency was not tested. In this study, although bilingual (Persian-Swedish) and monolingual (Swedish) children were matched with regard to socioeconomic status, they had different cultural backgrounds. The second study (Kormi-Nouri et al., 2008), comprising four experiments, was based on Iranian bilingual and monolingual children with matched socioeconomic status and similar cultural backgrounds, but the children were in different age groups (primary school, secondary school, and high school). Again, the results were mixed: bilingual advantage (in Experiments 3 and 4), bilingual disadvantage (Experiment 2), and no difference (Experiment 1).

Thus, we are still in need of a careful and systematic study of verbal fluency in child populations. In the present research, Iranian bilingual and monolingual boys and girls in primary school (aged 7-12 years) participated in both letter and category fluency tests. Both the monolingual and bilingual children lived in their home cities (Tehran, Tabriz, and Sanandaj), with their first languages (Persian, Turkish, and Kurdish, respectively) dominant or majority languages in their communities. In Tabriz, the dominant language at home is Turkish, whereas, in Sanandaj, it is Kurdish. The bilingual children spoke Turkish or Kurdish in their home, but received preschool and school programs in Persian. The monolingual children used Persian both at home and in school. In the present study, as in the Kormi-Nouri et al. $(2003,2008)$ studies, we adopted an intermediate definition of bilingualism, as suggested by Grosjean (1992). It assumes that bilingualism involves the regular use of two (or more) languages, and that bilinguals are people who need and use two (or more) languages in their everyday life.

Research has shown that verbal fluency is positively correlated with age, in the sense that the number of words generated in a verbal fluency task increases with age during childhood (e.g., Sauzéon et al., 2004; Strauss et al., 2006). Research has also shown that children are better at category fluency than letter fluency; they generate more words in category fluency than letter fluency tasks (e.g., Hurks et al., 2004). In the present study, since we used school grade as a factor representing age, this would provide us an opportunity to look at age-related verbal fluency development in the primary-school years.

Recent research has shown the importance of considering language proficiency in group comparison between monolingual and bilingual adults (Luo, Luk \& Bialystok, 2010). In the current study, in addition to exploring the correlation between age and verbal fluency among bilingual children we can also study the effect of Persian language proficiency on bilinguals with increasing age/academic grade. Our children were tested at the end of each academic year, from Grades 1 to Grade 5 in primary school. This means that our bilingual children in Grade 1 had one year experience of learning (especially reading and writing) the second language (Persian) academically at their primary schools. Gradually, this experience became longer for bilingual children from Grade 2 to 5 . Thus, the Persian-language proficiency of the bilingual children differed between Grades 1 (low level) and Grade 5 (high level) due to their academic experience. This provides us with an opportunity to investigate the effects of language proficiency on verbal fluency tasks. It should be noted that although our bilingual children (Turkish and Kurdish) had a non-Persian-speaking environment (at home) before entering primary schools; they were exposed to Persian environment occasionally by TV and kindergarten programs, and had some non-academic experience of learning Persian.

Our intention in using two bilingual groups was to see whether the language differences in bilinguals may entail a differential effect of bilingualism. Bialystok, Majumder and Martin (2003) showed that SpanishEnglish bilinguals performed better than Englishspeaking monolinguals on a phoneme segmentation task, but Chinese-English bilinguals performed worse. In verbal fluency tasks, Gollan et al. (2002) and Rosselli et al. $(2000,2002)$ included only Spanish-English bilinguals while the present study included bilinguals with distinct language pairs to explore potential differences in performance.

Since there is research showing some sex differences in fluency tasks (Bolla, Lindgren, Bonaccorsy \& Bleecker, 1990; Crossley, D’Arcy \& Rawson, 1997; Weiss et al., 2006), we controlled for this variable; half of the bilingual and monolingual children in each academic year were boys, and the other half girls.

Our study concerned verbal fluency tasks (letter and category) among bilingual and monolingual children. We hypothesized that the effects of bilingual advantage and/or disadvantage are not the same for letter and category fluency tasks. The two tasks are different by cognitive nature, and the bilingual effects might be expected to differ according to academic experience and language proficiency in the second language.

\section{Method}

\section{Design}

We used a 3 (Language: 2 bilingual and 1 monolingual groups $) \times 5$ (Grade) $\times 2$ (Verbal fluency task: letter and category) factorial design. The first two factors were used as between-subjects variables and the last factor was used as a within-subject variable. 


\section{Participants}

The total study group comprised 1,600 primary school children ( 800 boys and 800 girls): 600 (300 boys and 300 girls) from Tehran (Persian monolingual area), 500 (250 boys and 250 girls) from Tabriz (Turkish-Persian bilingual area), and 500 (250 boys and 250 girls) from Sanandaj (Kurdish-Persian bilingual area). The number of participants in each grade was 120 in Tehran and 100 in Tabriz and Sanandaj. We randomly selected 70 primary schools from different districts (north, south, and center) and from different types of schools (state, half-state, and private) in these three cities (30 schools in Tehran, 20 schools in Tabriz, and 20 schools in Sanandaj). This was done because the economic situations are not the same in different districts and schools of these cities. Bilingual (Turkish-Persian and Kurdish-Persian) and monolingual (Persian) children were also randomly selected from each of five grades (in Iran, there are five grades in primary school), and from among boys and girls. Four bilingual and monolingual boys and girls (in Tehran), or five (in Tabriz and Sanandaj), were randomly selected from each grade in all schools. The intention of using this selection procedure was to obtain samples of bilingual and monolingual children that were representative of their populations, and also as similar as possible with regard to socioeconomic factors.

All the bilingual and monolingual children in the present study had Iranian parents. The Turkish-Persian bilinguals spoke Turkish at home with their parents (both mothers and fathers had Turkish as their native language), and the Kurdish-Persian bilinguals spoke Kurdish at home with their parents (both mothers and fathers had Kurdish as their native language); all, however, received schooling programs in Persian. All monolinguals spoke Persian both at home with their parents (both mothers and fathers had Persian as their native language) and in school. The language of children and parents at home was ascertained by simply asking the children, their teachers, and parents. If either bilingual or monolingual children did not concur in these regards, they were excluded from the study.

It should be noted that Persian and Kurdish are more similar in certain linguistic aspects, such as phonology, morphology, and syntax, than are Persian and Turkish (Izadi, 1992). Kurdish is an Iranian language (spoken by about $7 \%$ of the Iranian population; Iran Country Review, 2003), and both Persian and Kurdish are Indo-European languages. These two languages show similarities at phonological, lexical, morphological, and syntactic levels. However, Turkish is a non-Indo-European language and its phonological, morphological, and syntactic properties are distinct from those of Kurdish and Persian. About $24 \%$ of the Iranian population speaks Turkish (Iran Country Review, 2003). Persian is the national and official language of Iran, and is used for instruction in all schools, in the media, and in administration (Nilipour, 1988).

\section{Measures}

\section{Letter Fluency Task}

We used nine letters for measuring letter fluency, three letters with high frequency $(\mathrm{A}, \mathrm{N}$, and $\mathrm{M})$, three with moderate fluency $(\mathrm{T}, \mathrm{H}$, and $\mathrm{L})$, and three with low frequency $(\mathrm{ZH}, \mathrm{CH}$, and $\mathrm{Y})$. These letters were selected on the basis of the number of words that start with those letters in the Persian lexicon, and the results of our previous study (Kormi-Nouri et al., 2008) and of a pilot study.

\section{Category Fluency Task}

Thirty-one categories were used in the present study. Most of the categories were taken from the Battig and Montague (1969) and Nilsson (1973) studies, but some were selected on the basis of our pilot study. The categories were: fourfooted animals, fruits, relatives, girls' first names, boys' first names, parts of the human body, kinds of clothes, colors, kitchen utensils, articles of furniture, metals, countries, cities, states, occupations or professions, sports, parts of buildings, musical instruments, birds, types of vehicles, toys, vegetables, insects, flowers, diseases, trees, non-alcoholic beverages, foods, school materials, sewing materials, and handicraft materials.

It should be noted that the presentation orders of the tests, both between the category and letter fluency tests and among the items in each test, were counterbalanced across bilingual and monolingual children.

\section{Procedure}

Each participant was tested individually. The experiment was conducted in Persian for all bilingual and monolingual children. Whenever it was necessary, the instructions were also given in the first language of the bilinguals (i.e., Turkish or Kurdish) to make sure that everyone understood and followed the instructions. This only took place during the instruction period, and as a double check, because the bilingual children were in different academic years and at different levels of language proficiency in Persian. However, if the examiners found that participants could not follow the instruction and experiments in Persian and this was ascertained by their teachers' examination, they were excluded from the study. The rate of exclusion was about 3\%. The experiment started with giving the instructions, and two examples of letters and categories. The letters and categories were presented to all children one by one, a maximum of three minutes given for each. The children were asked to produce as many words starting with these initial letters or belonging to these categories as they could (in any order). 




Note: In letter fluency, there was a significant bilingual advantage for Turkish-Persian bilinguals in Grade 1, while, there was a significant bilingual disadvantage for Kurdish-Persian bilinguals in Grade 5 $(p s<.05)$. In category fluency, there were bilingual disadvantages for Turkish-Persian bilinguals in Grades 4 and 5, and for Kurdish-Persian bilinguals in Grades 3, 4, and 5 ( $p$ s $<.05$ ).

Figure 1. Average mean numbers of correctly generated word across nine letters and 31 categories in different language groups and academic grades.

In adult studies, there is usually one minute as a time limit for each letter and category (Strauss et al., 2006) although other variants of administration may be also found in the literature (e.g., Jurado et al., 2000; Tucha, Smely \& Lange, 1999). In the present study, since children need more time for cognitive performance, a maximum time of three minutes was used. We did not want to introduce time pressure as a stressful factor for the children. The children were allowed to stop at any individual letter or category cue whenever they had no further words to produce (after asking them twice to make sure that this was the case). The actual times used by children were measured by stopwatch, beyond the children's sight and attention. That is, an attempt was made to ensure that the children were unaware of time measurement (so as to eliminate any possible stress).

The children generated words orally, and their responses were recorded on tape, and also written down by the experimenters on special forms. The whole experiment lasted 68 minutes on average for each child (16 minutes for letter fluency, and 52 minutes for category fluency), and was performed in two sessions (with an approximate one-hour interval between the two sessions).

\section{Results}

We conducted a 3 (Language) $\times 5$ (Grade $) \times 2$ (Task) multi-factorial ANOVA on average mean numbers of words generated across 9 letters and 31 categories by one group of monolingual and two groups of bilingual children (shown in Figure 1). This ANOVA showed that the main effect of language was significant $[F(2,1585)=43.75$, $M S e=6041.88, p<.001]$. A post hoc analysis indicated

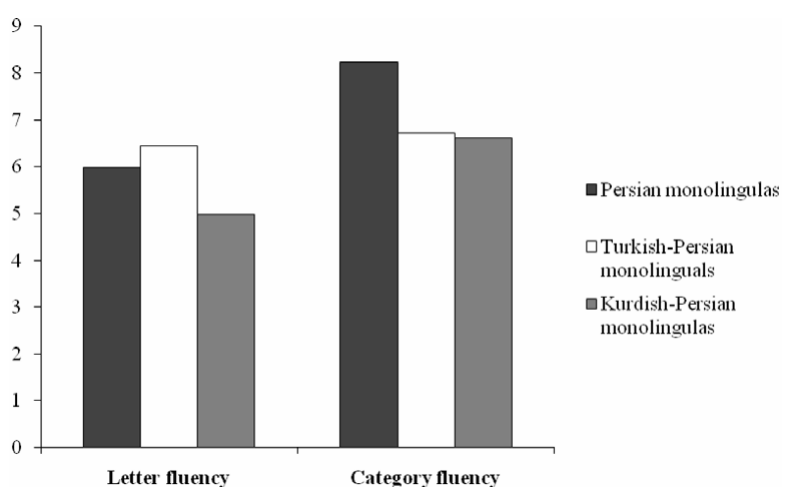

Note: In category fluency, there are significant bilingual disadvantages for both bilingual groups $(p \mathrm{~s}<.05)$.

Figure 2. Average mean numbers of correctly generated words in two fluency tasks and different language groups.

that the mean of the total words generated by monolingual children (7.12) was greater than that generated by both bilingual children (Turkish-Persian bilinguals $=6.58$, Kurdish-Persian bilinguals $=5.80$ ).

The main effect of Grade was also significant $[F(4,1585)]=150.39, M S e=6041.88, p<.001]$. A post hoc analysis indicated that, the production of words increased from grade 1 to grade $5(4.38,5.31,6.53,7.58$, 8.66 , respectively), steadily and systematically. The main effect of task was also significant $[F(1,1585)]=9519.66$, $M S e=2424.20, p<.001]$ indicating that mean words generated in the category fluency task (7.19) were greater than the letter fluency task (5.81).

Language $\times$ Task interaction (shown in Figure 2) was significant $[F(2,1585)]=85.32, \quad M S e=2424.20$, $p<.001]$. A post hoc analysis indicated that, in the category fluency task, monolingual children (8.24) performed better than both bilingual children (Turkish-Persian bilinguals $=6.72$, Kurdish-Persian bilinguals $=6.61$ ). In the letter fluency task, there was no difference between monolingual (5.99) and bilingual children (Turkish-Persian bilinguals $=6.45$, KurdishPersian bilinguals $=4.98$ ). This interaction effect also showed that the superiority in the category fluency task over letter fluency task was significant for Persian monolinguals (8.24 vs. 5.99) and KurdishPersian bilinguals $(6.61$ vs. 4.98$)(p \mathrm{~s}<.01)$ but not for Turkish-Persian bilinguals (6.72 vs. 6.45) $(p>.30)$. The significant interaction effect between Grade and Task $[F(4,1585)]=166.55, \quad M S e=2424.20, p<.001]$ also indicated that the increase of word production from Grades 1 to 5 was more pronounced in the category fluency task than in the letter fluency task.

Language $\times$ Grade $\times$ Task interaction was also significant $[F(8,1585)]=16430.73, M S e=2424.20, \quad p<$ $.001]$. A post hoc analysis indicated that the 
Language $\times$ Grade interaction was different in two types of fluency tasks. In the category fluency task, monolingual children outperformed both bilingual children (more pronounced for Turkish-Persian bilinguals) in Grades 1 and 2 (non-significantly) and then in Grades 3, 4 and 5 (significantly). In the letter fluency task, Turkish-Persian bilingual children had significantly better performance than monolingual children in Grade 1. All three groups in Grades 2-5 showed no difference in performance. There was an exception only for Kurdish-Persian bilinguals who performed significantly worse than monolinguals in Grade 5.

Two separate 3 (Language) $\times 5$ (Grade) univariate AVOVAs were also conducted for each of letter and category fluency task. The first univariate ANOVA for letter fluency task showed that the main effect of Language was significant $[F(2,1585)=17.34$, $M S e=163.03, p<.001]$. A post hoc analysis indicated that, although the mean of the words generated by Turkish-Persian bilinguals (6.45) was greater than that generated by Persian monolinguals (5.99), the difference did not reach significance $(p>.20)$. But, these two groups (Turkish-Persian bilinguals and Persian monolinguals) generated significantly more words than Kurdish-Persian bilinguals (4.98) ( $p$ s $<.01)$.

The main effect of Grade was also significant $[F(4,1585)]=31.85, M S e=163.03, p<.01]$. A post hoc analysis indicated that, although the production of words increased from Grade 1 to Grade 5, steadily and systematically, the differences between Grade 1 (4.17) and Grade 2 (4.72) and between Grade 3 (5.85) and Grade 4 (6.66) were not significant $(p s>.10)$. Children in Grade 5 (7.64) generated significantly more words than the children in the other grades. Children in Grades 3 and 4 produced significantly more words than children in Grades 1 and 2.

The interaction between Language and Grade was significant $[F(8,1585)=3.10, M S e=163.03, p<.01]$. A post hoc analysis showed that the increase in generated words from Grade 1 to Grade 5 was more pronounced among Persian monolinguals than among the two bilingual groups. Furthermore, it was shown that, whereas Turkish bilinguals significantly produced more words than Persian monolinguals in Grade 1 (5.90 vs. 3.37, respectively), Kurdish bilinguals significantly produced fewer words than Persian monolinguals in Grade 5 (5.98 vs. 9.16, respectively) ( $p s<.05)$.

The second univariate ANOVA for category fluency task showed that the main effect of Language was significant $[F(2,1585)=69.97, M S e=203.74, p<.01]$. A post hoc analysis showed that Persian monolinguals produced more words in the categories than TurkishPersian bilinguals and Kurdish-Persian bilinguals $(p s<.01)$. There was no significant difference between the two groups of bilinguals (Turkish-Persian and Kurdish-
Persian). The main effect of Grade was significant $[F(4,1585)=212.75, M S e=203.74, p<.01]$. A post hoc analysis indicated that the differences between all grades (Grade $1=4.59$, Grade $2=5.89$, Grade $3=7.20$, Grade $4=8.58$, and Grade $5=9.67$ ) were significant.

The interaction between language and grade was significant $[F(8,1585)=7.85, M S e=203.74, p<.01]$. A post hoc analysis showed that increasing production of words (from Grade 1 to Grade 5) was more pronounced for monolinguals than for bilinguals. Furthermore, it was also shown that whereas Turkish bilinguals produced fewer words than Persian bilinguals in Grades 4 and 5, Kurdish bilinguals produced fewer words in Grades 3, 4, and 5.

As was noted in the method section above, gender was used as control variable in the present study. Since the descriptive statistics for gender can benefit subsequent research, especially from the large sample size, the data are reported in a separate appendix.

\section{Discussion}

In this study, bilingual and monolingual children were found to perform differently on letter and category fluency tasks, and it seems that there is dissociation between the two tasks among bilinguals. In the letter fluency task, Turkish-Persian bilinguals outperformed Persian monolinguals; although the overall effect did not reach significance, they performed significantly better than their Persian monolingual peers in Grade 1. However, the bilingual advantages systematically decreased over grades 2, 3, and 4, finally ending up with a non-significant bilingual disadvantage in Grade 5. A similar pattern was observed for Kurdish-Persian bilinguals, but with some exceptions: the bilingual advantage was not significant in Grade 1, but the bilingual disadvantage was significant in Grade 5. Overall, these findings are in line with those of the Kormi-Nouri et al. (2003, 2008) studies, in which bilinguals were found to perform better than monolinguals on the letter fluency test. They are also in line with Bialystok and colleagues (e.g., Bialystok, Craik, Klein \& Viswanathan, 2004; Bialystok, Craik \& Ryan, 2006) showing better performance among bilinguals than monolinguals in other cognitive tasks where conflict is needed to be resolved.

The bilingual advantages can be explained by extensive practical experience of two languages at early ages in bilingual children, who thereby become more able than their monolingual counterparts to focus on parts of a body of information and inhibit other parts (Bialystok, 2001, 2004, 2005). Francis (1999) presumed that the effect of bilingualism is due to the integration of two languages in children, and the information in one language is intentionally or automatically accessible to the other. This gives an advantage to bilinguals, in that they are more 
flexible in using the information they have in memory in two languages.

However, in the category fluency task, monolingual children performed better than bilingual children. The bilingual disadvantage started in Grade 1 (but not for Kurdish-Persian bilinguals) and continued progressively and significantly in other school grades (Grades 4 and 5 for Turkish-Persian bilinguals and Grades 3, 4, and 5 for Kurdish-Persian bilinguals). These findings are in line with some research in the literature. Gollan et al. (2002) reported a memory disadvantage for bilingual adults in a semantic category task, and also found a bigger bilingual disadvantage for semantic fluency than for letter fluency. Further, Rosselli et al. (2000) and Portocarrero et al. (2007) found that bilingual adults produced fewer correct responses in a category task. They presumed that semantic categories are more vulnerable to the effects of cross-language interference. The results of the present study are in line with Gollan et al (2002), Rosselli et al. (2000) and Portocarrero et al. (2007), and extended their findings of bilingual disadvantage on category fluency tasks from adult population to a child population, and from Spanish-English bilinguals to Persian-Turkish and Persian-Kurdish bilinguals.

Rosselli et al. (2000) discussed the difference between bilinguals and monolinguals in relation to dissociation on letter and category fluency tasks. They explained such dissociation in terms of the nature or specific characteristic of each task: the dependence of category fluency on lexical knowledge as opposed to the dependence of letter fluency on executive function; and the concreteness of categoryfluency words (which are shared between two languages) as opposed to the non-concreteness of letter-fluency words (which exist in just one language).

An alternative hypothesis, based on above suggestions, is that category fluency involves activation of lexical candidates in both languages, whereas letter fluency involves activation of candidates in just one language only. On this view, the essential difference between the tasks has to do with the type of interference created, rather than with the difference between lexical and executive function. In such a case, the performance of bilinguals in letter fluency is higher because there is no interference, but the performance of bilinguals in category fluency is lower because searching for words across languages involves interference.

There are also several studies in the literature that demonstrate differential effects of bilingualism on cognitive tasks (Bialystok, 2008; Bialystok, Craik \& Luk, 2008b; Bialystok \& Senman, 2004; Gollan \& Acenas, 2004; Gollan, Montoya, Fennema-Notestine \& Morris, 2005; Martin-Rhee \& Moniri, 2006). For example, Bialystok et al. (2008b) reported that, whereas bilinguals performed better than monolinguals in executive control tasks, monolinguals performed better than bilinguals in lexical retrieval tasks. Gollan et al. (2005) reported that bilinguals and monolinguals differed with regard to picture-naming and picture-classification tasks. Bilinguals were slower and made more errors than monolinguals in picture naming, but bilinguals classified pictures as quickly as monolinguals.

Another explanation for the dissociation between category and letter fluency could be due to different cognitive demands underlying the two tasks. In the present study, this was indicated by the children (only monolingual and Kurdish-Persian bilinguals) producing more exemplar words in category fluency tasks than in letter fluency tasks. It is possible that bilingualism is associated with superiority on tasks demanding higher levels of cognitive demands. That is, the greater the demands of the cognitive task, the greater the bilingual advantage that can be expected.

This might be also the reason why superiority of category over letter fluency tasks was not observed for Turkish-Persian bilinguals. Category fluency requires access to semantic knowledge, whereas letter fluency relies on phonological/lexical retrieval mechanisms (Butters et al., 1987). Normal subjects have greater difficulty in producing words by letter than by category, since retrieval of semantic knowledge is commonplace in everyday life, whereas letter retrieval is less related to day-to-day living (Rosen, 1980). Letter fluency tasks are relatively new to most participants, and are likely to require more executive functions than category fluency tasks (Hurks et al., 2004). Bokat and Goldberg (2003), from reviewing other studies, concluded that the production of exemplars for letter fluency can be accomplished by using phonemic or orthographic cues, and is dependent on the functioning of the left prefrontal cortex and left inferior parietal cortex. By contrast, category fluency needs subjects understand the attributes an exemplar should possess in order to meet the category inclusion criteria and function on this task requires resources from both the frontal and temporal brain regions.

A similar dissociative effect of category and letter fluency tasks has been found in patients with neurological complaints. Joyce, Collinson and Crichton (1996) reported impairment of both semantic and letter fluency in patients with schizophrenia. However, the normal pattern of category fluency being superior to letter fluency remained, and category fluency improved when a cuing technique was employed. It has also been shown that Parkinson patients perform better at category fluency than letter fluency (Gabrieli, Singh, Stebbins \& Goetz, 1996). However, Azuma et al. (1997) reported that it is not always the case that category fluency is superior to letter fluency. Alzheimer's patients have more difficulty with semantic fluency than with letter fluency (Butters et al., 1987; Rosser \& Hodges, 1994). 
It might be argued that our bilingual children were being tested in their non-dominant language (Persian) while the monolingual children were tested in their onedominant language. This gave therefore a disadvantage to bilinguals compared to monolinguals. We have three responses for this argument. First, it should be noted that we adopted an intermediate definition of bilingualism (Grosejean, 1992) suggesting that bilinguals should use two (or more) languages in their everyday life. Our bilinguals used their second language (Persian) at school and their first language (Turkish or Kurdish) at home on a daily basis. The bilingual children had also some experience of Persian training in preschool period through kindergarten and TV programs. It was also one of our exclusion criteria that the bilingual children were tested for their Persian language proficiency by their teachers' examination and if they did not have appropriate Persian knowledge according to their ages they were excluded from the study. Thus, the claim is that our bilingual children fitted with the intermediate definition of bilingualism and had good knowledge of Persian (especially in speaking and listening) according to their ages/academic grades. Second, Kormi-Nouri et al. (2008) by using Turkish-Persian bilinguals (with the same definition as the present study) in Grades 3 and 11 and testing letter fluency task in their first and second languages showed that, in both Grades 3 and 11 and in both languages, bilingual children outperformed their counterpart Persian monolinguals. More interestingly, the bilingual advantage was more pronounced where bilinguals were tested in their second language than in their first language. Third, even by accepting a possible disadvantage for bilinguals when they are tested in their second language, the procedure used in the present study was similar for both category and letter fluency tasks. Yet, we observed a differential effect for these two tasks; bilingual disadvantage for category task and bilingual advantage or no difference for letter fluency task. It is important to emphasize that the fact that bilinguals are tested in a non-dominant language may imply that bilingual advantages become harder to see than bilingual disadvantages. Taken together, it seems that being tested in second language is not an important issue for bilinguals in the present study; rather it is the nature of two cognitive tasks that is an important issue here, and this provides a dissociative effect on bilingualism.

Portocarrero et al. (2007) suggested that cultural differences may influence performance on some categories. In the current study, since the bilingual and monolingual children were all Iranians who lived in their home cities with their native language as the dominant and majority language, they had greater similarity in their cultural background than the bilinguals and monolinguals that did not share the same background in previous studies. Despite this similarity, however, there is still dissociation in the performances of bilinguals relative to monolinguals in category fluency and letter fluency. Moreover, the general pattern of results for bilingual advantages and disadvantages was similar for the two groups of Turkish-Persian and Kurdish-Persian bilinguals, which also puts some doubts on the possibility of language/culture difference. Thus, it can be concluded that cultural background is not mainly responsible for the dissociation observed in the two types of fluency tasks for bilinguals and monolinguals. Rather, it seems that specificity and nature of cognitive task is a more important factor.

In the present study, despite generally similar findings for the two groups of bilinguals, we also found some differences: the bilingual disadvantages were more pronounced for Kurdish-Persian bilinguals, whereas the bilingual advantages were more pronounced for TurkishPersian bilinguals. Furthermore, the typical superiority of category over letter fluency was observed for Kurdish-Persian bilinguals, similar to that for Persian monolinguals, but it was not observed for Turkish-Persian bilinguals. One explanation concerning more bilingual disadvantage for Kurdish-Persian bilinguals, might be due to a possible socioeconomic status (SES) confound for our bilingual groups. Although an attempt was made to match between bilingual and monolingual groups with respect to their SES in terms of the selection of districts and schools in these cities, there may be still a place for such confounding because the groups were drawn from different communities with different social and economic conditions. This may be especially the case for the Kurdish children who belong more to minority population $(7 \%$ of Iranian population) than the Turkish children (24\% of population) in Iran. Another explanation concerning the lack of superiority of category over letter fluency for Turkish-Persian bilinguals might be due to language differences. The comparison between the two languages in the present study and the comparison between different languages in this study and Gollan et al. and Rosselli et al. studies indicate that the bilingual effects might be different from one language to another. Accordingly, we have to acknowledge these limitations of the present study and the need for a systematic and careful cross-cultural and cross-linguistic study about the nature and structure of languages and their effects on bilingualism in future research.

Recent research (Luo et al., 2010) has shown that, for adult bilinguals, language proficiency (indicated by vocabulary performance in the second language) has a dissociable effect in letter and category fluency tasks. It might be questioned whether there is an effect of language proficiency in bilingual children. In the present research, the question was: How can the improvement of second language (Persian) in bilingual children affect bilingual advantage and disadvantage in category and 
letter fluency tasks differently? To answer this question we need to focus on interaction between language and grade with regard to these two tasks. Since our bilingual children lived in their own communities with their native languages, and had only schooling in their second language (Persian), each academic year (grade) at school can be considered as boosting their language proficiency in Persian. That is, bilingual children in Grade 1 had the lowest language proficiency in Persian, whereas bilingual children in Grade 5 had the highest. In the present study, in the lower grades of primary school, we observed either a bilingual advantage or no difference between bilinguals and monolinguals for both letter and category fluency tasks, whereas in the higher grades, the bilingual disadvantages were more observable.

One explanation for these findings might be that the greater language proficiency in Persian of bilingual children in higher grades results in more matching and balancing between their two languages, and thereby gives rise to greater interference between them. This reasoning is in line with the findings of Gollan et al. (2002), which suggest that cross-language interference is responsible for bilingual disadvantage and occurs when the first and second languages are in balance; such interference is more pronounced for category fluency tasks than for letter fluency tasks. Our study showed that the bilingual disadvantage in higher grades was more pronounced for category tasks than for letter tasks. However, there is an alternative explanation, namely that although bilinguals improve their second language (Persian) over the academic years, their first language is steadily impoverished. That is, there might be greater imbalances between the two languages in higher grades than in lower grades. Our bilingual children received no formal education (especially in reading and writing) in school in their first languages, but Persian, as the official language, was taught to all the children (bilingual and monolingual). This might be why we found a bilingual advantage or no differences in lower grades, but a bilingual disadvantage in higher grades. It should also be noted that children's language in lower grades (especially Grade 1) is more based on phonological processing than it is in higher grades, where it depends more on orthographic processing (e.g., Frith, 1986). This might be a good reason why our bilingual children in Grade 1, who were still doing phonological processing in their two languages, showed a bilingual advantage. This advantage was found to be more pronounced on the letter fluency test, which is more specifically based on phonological processing (Melinder, Barch, Heydebrand \& Csernansky, 2005). On the other hand, in higher grades, where there is scope for more semantic or orthographic processing, our bilingual children, who were at disadvantage with regard to orthographic processing in their first languages, showed a bilingual disadvantage. This effect was more pronounced for category fluency tasks than for letter fluency tasks.

Support for the second explanation comes from KormiNouri et al. (2003) study, where bilingual children (Persian-Swedish) were given reading and writing opportunities in both languages in their Swedish primary schools (although not identically and at the same level). In this study, the bilingual advantage was more pronounced in Grade 6 than in Grade 2. On the other hand, the Kormi-Nouri et al. (2008) study, by using Iranian bilinguals (Turkish-Persian) without reading and writing opportunities in their first language, found opposite results and similar to ours in the present study, namely the bilingual advantage was more pronounced for younger children than for older children. However, this effect was observed only in the two experiments (Experiments 1 and 2) and not in the other two experiments (Experiments 3 and 4). We do not have a good explanation for these inconsistent findings yet, except perhaps that there was a methodological difference in using different exemplar and number of letter fluency tasks. Hence, these mixed results do not let us to draw a clear conclusion and we are still in need of further experimental work. However, it is important to note that almost all studies comparing monolinguals and bilinguals have quasi-experimental designs. To test these alternative ideas about the effect of language proficiency on verbal fluency, we need a longitudinal study with the experimental condition that bilinguals with an equal opportunity to read, write and speak in both their languages are compared with a control group where there is no such opportunity.

In line with previous research (e.g., Sauzéon et al., 2004, Strauss et al., 2006), our findings showed that verbal fluency (both category and letter) was positively correlated with age/school year, in the sense that the number of words generated in a verbal fluency task increased with age/academic grade during school years. However, the results showed that this increase was more pronounced for monolingual children than for bilingual children and the bilingual disadvantage was more observable in later ages/grades than in early ages/grades. These findings are surprising and contrary to ideas in the literature that bilinguals are disadvantaged early and then "catch up" with monolinguals later (see Hamers \& Blanc, 2000 for review). Once again, our findings refer to the two above-discussed notions. The first notion was about the differential effects of category and letter fluency on bilingualism since there was more bilingual disadvantage for category than for letter fluency tasks in higher grades than in lower grades. The second notion was about language proficiency for bilinguals' first language in the sense that our bilinguals had no formal education in their fist language in school years and had greater imbalance between the two languages in higher grades than in lower grades. 
Finally, it should be noted that the choice of letter and category set affects the results of bilingualism to some extent because of differences in letter and category difficulty, and word frequency for each letter and category (Borkowski et al., 1967). As is shown in Appendix 1 and 2, there were some of the letters and categories that produce a bilingual advantage or disadvantage. In the present study, we selected nine letters according to their frequencies (low, moderate, and high) in Persian lexicons and some previous studies. Although, as was expected, children generated more words with highfrequency letters than with moderate-frequency letters and than, in turn, with low-frequency letters, we found no systematic relationship between word frequency and bilingualism. It seems that the number of words beginning with a given letter produced by participants is not directly related to the effect of bilingualism. On the other hand, there may be some linguistic, geographical, and sociological explanations of the levels of production of words in different groups of participants (Strauss et al., 2006). The present study did not have any control over these factors and we need to control these factors in future research.

In summary, our study shows different performances of bilingual children in letter and category fluency, and different bilingual advantages and disadvantages. The finding is dissociative, in that there is bilingual advantage for letter fluency and bilingual disadvantage for category fluency. This finding is consistent with those of previous studies of the consequences of bilingualism for verbal fluency. Bilingualism influences cognitive control and language representation differently from monolingualism, as reflected in performance of these tasks. Furthermore, this study suggests that levels of language proficiency in bilinguals should be taken into account as mediator variables in future studies.

Appendix 1. Mean numbers of correct responses of bilingual and
monolingual boys and girls for each letter

\begin{tabular}{|c|c|c|c|}
\hline & $\begin{array}{l}\text { Persian } \\
\text { monolinguals }\end{array}$ & $\begin{array}{l}\text { Turkish-Persian } \\
\text { bilinguals }\end{array}$ & $\begin{array}{l}\text { Kurdish-Persian } \\
\text { bilinguals }\end{array}$ \\
\hline \multicolumn{4}{|l|}{ BOYS } \\
\hline A & $11.35(17.92)$ & $5.11(3.53) \#$ & $6.97(6.84) \#$ \\
\hline $\mathrm{N}$ & $6.57(5.03)$ & (14.00) & $5.62(4.19)$ \\
\hline M & $9.29(6.73)$ & $5.70(5.28) \#$ & $7.56(5.22)$ \\
\hline $\mathrm{T}$ & $5.68(4.25)$ & $6.04(7.28)$ & $5.68(3.72)$ \\
\hline $\mathrm{H}$ & $3.33(3.14)$ & $12.42(22.06) \mathrm{d}$ & $4.78(3.57)$ \\
\hline $\mathrm{L}$ & $4.41(3.36)$ & $10.92(18.71) \alpha$ & $4.31(2.83)$ \\
\hline $\mathrm{ZH}$ & $2.46(1.50)$ & 9.88(18.75) & $3.08(1.88)$ \\
\hline $\mathrm{CH}$ & $5.48(3.89)$ & $3.76(3.76)$ & $5.77(3.79)$ \\
\hline $\mathrm{Y}$ & $2.99(2.68)$ & $2.80(4.70)$ & $3.74(3.17)$ \\
\hline Total & $51.75(35.28)$ & 64.34 (64.14) & $47.51(27.41)$ \\
\hline \multicolumn{4}{|l|}{ GIRLS } \\
\hline A & $10.08(8.60)$ & $8.90(13.73)$ & $6.68(7.37) \#$ \\
\hline $\mathrm{N}$ & $8.09(5.53)$ & $7.27(7.49)$ & $4.78(3.27) \#$ \\
\hline M & $11.15(7.00)$ & $10.10(6.42)$ & $7.04(5.01) \#$ \\
\hline $\mathrm{T}$ & $6.04(4.12)$ & $4.86(3.30)$ & $4.83(3.26)$ \\
\hline $\mathrm{H}$ & $4.08(3.53)$ & $3.61(6.56)$ & $4.21(2.80)$ \\
\hline $\mathrm{L}$ & $5.44(4.08)$ & $5.14(6.87)$ & $3.46(2.28)$ \\
\hline $\mathrm{ZH}$ & $2.68(1.45)$ & $2.84(6.27)$ & $3.31(1.70)$ \\
\hline $\mathrm{CH}$ & $5.94(4.05)$ & $5.90(7.07)$ & $5.59(3.86)$ \\
\hline $\mathrm{Y}$ & $3.43(2.45)$ & $3.08(8.90)$ & $2.22(2.25)$ \\
\hline Total & $56.35(32.92)$ & $51.50(54.54)$ & $42.12(21.99)$ \\
\hline
\end{tabular}

Note: The values in parentheses are standard deviations; \#=significant bilingual disadvantages; $\bigcirc=$ significant bilingual advantages $(p<.05)$. 


\section{Appendix 2. Mean numbers of correct responses of bilingual and monolingual boys and girls for each category}

\begin{tabular}{|c|c|c|c|}
\hline & $\begin{array}{l}\text { Persian } \\
\text { monolinguals }\end{array}$ & $\begin{array}{l}\text { Turkish-Persian } \\
\text { bilinguals }\end{array}$ & $\begin{array}{l}\text { Kurdish-Persian } \\
\text { bilinguals }\end{array}$ \\
\hline \multicolumn{4}{|l|}{ BOYS } \\
\hline relatives & $7.69(6.90)$ & $6.28(5.57)$ & $7.18(3.67)$ \\
\hline four-footed animals & $8.95(4.10)$ & $7.64(3.64)$ & $8.40(3.63)$ \\
\hline fruits & $11.13(4.11)$ & $9.32(4.32)$ & $9.09(3.05)$ \\
\hline girls' first names & $12.63(7.43)$ & $10.75(7.53)$ & $10.61(4.74)$ \\
\hline boys' first names & $17.27(9.04)$ & $15.91(10.04)$ & $13.92(5.80)$ \\
\hline parts of human body & $14.15(7.94)$ & $16.88(18.41)$ & $11.25(4.18)$ \\
\hline kinds of clothes & $7.51(4.55)$ & $5.89(3.48)$ & $7.26(3.29)$ \\
\hline colors & $10.82(3.13)$ & $8.80(2.48)$ & $8.81(5.10)$ \\
\hline kitchen utensils & $10.12(5.08)$ & $6.74(3.77)$ & $8.24(3.46)$ \\
\hline articles of furniture & $10.44(5.28)$ & $8.40(4.97)$ & $8.29(3.51)$ \\
\hline metals & $1.67(2.00)$ & $10.46(21.14) \propto$ & $2.50(1.99)$ \\
\hline countries & $10.79(9.01)$ & $5.62(6.80) \#$ & $8.26(5.42)$ \\
\hline cities & $7.90(8.99)$ & $6.39(5.97)$ & $8.20(4.70)$ \\
\hline states & $4.32(4.84)$ & $3.01(4.12)$ & $4.89(3.94)$ \\
\hline occupations & $9.56(6.62)$ & $5.60(5.70)$ & $8.54(4.28)$ \\
\hline sports & $7.79(5.00)$ & $5.53(5.31)$ & $6.94(3.24)$ \\
\hline parts of buildings & $4.42(4.33)$ & $2.74(3.58)$ & $5.31(3.49)$ \\
\hline musical instruments & $3.07(3.19)$ & $2.88(4.15)$ & $3.95(2.47)$ \\
\hline birds & $7.55(3.90)$ & $4.60(3.33)$ & $6.73(3.35)$ \\
\hline types of vehicles & $5.19(3.19)$ & $3.43(3.36)$ & $6.02(2.81)$ \\
\hline toys & $7.46(4.11)$ & $7.01(3.93)$ & $5.72(2.80)$ \\
\hline vegetables & $4.17(2.70)$ & $3.13(2.71)$ & $4.46(2.72)$ \\
\hline insects & $4.54(2.15)$ & $2.61(2.81)$ & $4.11(1.78)$ \\
\hline flowers & $4.68(2.47)$ & $2.46(2.05)$ & $4.51(3.66)$ \\
\hline diseases & $5.48(4.39)$ & $5.56(6.06)$ & $5.60(3.95)$ \\
\hline trees & $6.17(3.80)$ & $8.42(8.01)$ & $6.19(2.56)$ \\
\hline non-alcoholic beverages & $5.49(3.44)$ & $4.50(3.19)$ & $4.87(1.98)$ \\
\hline foods & $10.92(5.28)$ & $5.54(3.04)$ & $7.25(3.08)$ \\
\hline school materials & $8.35(4.44)$ & $8.90(12.27)$ & $7.58(2.89)$ \\
\hline sewing materials & $4.41(2.10)$ & $10.50(18.20) \alpha$ & $4.40(1.89)$ \\
\hline handcraft materials & $6.21(4.50)$ & $3.56(4.31) \#$ & $5.68(3.10)$ \\
\hline Total & $240.86(108.68)$ & 209.08(120.46)\# & $214.74(77.88) \#$ \\
\hline \multicolumn{4}{|l|}{ GIRLS } \\
\hline relatives & $10.70(7.53)$ & $9.06(5.90)$ & $7.93(4.17)$ \\
\hline four-footed animals & $8.13(4.36)$ & $6.69(3.48)$ & $6.36(3.27)$ \\
\hline fruits & $12.42(4.66)$ & $10.66(4.20)$ & $11.01(14.12)$ \\
\hline girls' first names & $25.78(11.59)$ & $24.44(11.03)$ & $14.87(5.27)$ \\
\hline boys' first names & $18.21(9.11)$ & $18.22(10.19)$ & $12.22(5.61)$ \\
\hline parts of human body & $15.69(7.23)$ & $11.21(5.98) \#$ & $10.58(7.30) \#$ \\
\hline kinds of clothes & $8.96(4.49)$ & $8.12(4.02)$ & $7.06(2.93)$ \\
\hline colors & $12.81(3.44)$ & $10.55(2.98)$ & $9.10(2.51)$ \\
\hline kitchen utensils & $11.82(5.27)$ & $8.40(4.49) \#$ & $7.63(3.80) \#$ \\
\hline articles of furniture & $11.37(5.22)$ & $9.45(4.99)$ & $7.66(3.35)$ \\
\hline metals & $1.29(1.75)$ & $0.76(1.57)$ & $1.51(1.73)$ \\
\hline
\end{tabular}




\section{Appendix 2. Continued}

\begin{tabular}{lccc}
\hline \hline countries & $7.66(6.44)$ & $4.77(5.12) \#$ & $4.70(4.22) \#$ \\
cities & $7.97(6.53)$ & $7.82(6.43)$ & $7.13(4.50)$ \\
states & $3.91(4.95)$ & $3.12(4.25)$ & $3.93(3.83)$ \\
occupations & $9.61(6.25)$ & $7.66(6.23)$ & $6.66(3.79) \#$ \\
sports & $6.17(3.87)$ & $4.02(3.20)$ & $4.56(2.88)$ \\
parts of buildings & $5.33(4.48)$ & $2.60(3.20)$ & $4.74(3.23)$ \\
musical instruments & $2.98(3.06)$ & $0.98(1.54)$ & $2.35(2.49)$ \\
birds & $7.19(3.62)$ & $4.90(3.14)$ & $4.65(2.79)$ \\
types of vehicles & $4.97(2.79)$ & $3.52(3.34)$ & $4.13(2.56)$ \\
toys & $8.53(4.88)$ & $8.95(4.96)$ & $5.92(3.36)$ \\
vegetables & $4.98(3.00)$ & $3.41(3.35)$ & $4.33(2.68)$ \\
insects & $4.39(2.44)$ & $2.77(2.75)$ & $3.34(2.50)$ \\
flowers & $6.81(3.26)$ & $4.69(3.03)$ & $4.97(3.33)$ \\
diseases & $6.97(4.93)$ & $4.55(4.30)$ & $4.91(3.14)$ \\
trees & $6.43(4.42)$ & $6.54(3.77)$ & $5.29(3.02)$ \\
non-alcoholic beverages & $6.17(3.37)$ & $5.25(3.56)$ & $4.48(2.69)$ \\
foods & $12.89(5.98)$ & $8.28(4.77) \#$ & $7.13(3.31) \#$ \\
school materials & $9.45(4.88)$ & $5.60(4.83) \#$ & $6.81(2.94)$ \\
sewing materials & $5.31(2.23)$ & $3.85(2.56)$ & $4.27(2.19)$ \\
handcraft materials & $7.47(4.45)$ & $4.34(4.18) \#$ & $4.54(3.50) \#$ \\
Total & $269.71(110.01)$ & $207.34(103.22) \#$ & $194.80(77.32) \#$ \\
\hline \hline
\end{tabular}

Note: The values in the parentheses are standard deviations; $Q \mathbf{Q}=$ significant bilingual advantages; \#= significant bilingual disadvantages $(p<.05)$.

\section{References}

Anastasi, A., \& Cordova, F. A. (1953). Some effects of bilingualism upon the intelligence test performance of Puerto Rican in New York City. Journal of Educational Psychology, 44, 1-19.

Azuma, T., Bayles, K. A., Cruz, R. F., Tomoeda, C. K., Wood, J. A., McGeagh, A., \& Montgomery, E. B. (1997). Comparing the difficulty of letter, semantic, and name fluency tasks for normal elderly and patient with Parkinson's disease. Neuropsychology, 11 (4), 488-497.

Battig, W. F., \& Montague, W. E. (1969). Semantic memory functioning across the adult life span. European Psychologists, 1, 27-33.

Bialystok, E. (1999). Cognitive complexity and attentional control in bilingual mind. Child Development, 70 (3), 636644.

Bialystok, E. (2001). Bilingualism in development: Language, literacy, and cognition. Cambridge: Cambridge University Press.

Bialystok, E. (2004). Impact of bilingualism on language and literacy development. In T. K. Bhatia \& W. C. Ritchie (eds.), The handbook of bilingualism, pp. 577-601. Oxford: Oxford University Press.

Bialystok, E. (2005). Consequences of bilingualism for cognitive development. In J. F. Kroll \& A. M. B De Groot (eds.), Handbook of bilingualism: Psycholinguistic approach, pp. 417-432. New York: Oxford University Press.
Bialystok, E., Craik, F. I. M., Klein, R., \& Viswanathan, M. (2004). Bilingualism, aging, and cognitive control: Evidence from the Simon task. Psychology and Aging, 19, 290-303.

Bialystok, E., Craik, F. I. M., \& Luk, G. (2008a). Lexical access in bilinguals: Effects of vocabulary size and executive control. Journal of Neurolinguistics, 21, 522-538.

Bialystok, E., Craik, F. I. M., \& Luk, G. (2008b). Cognitive control and lexical access in younger and older bilinguals. Journal of Experimental Psychology: Learning, Memory, and Cognition, 34 (4), 859-873.

Bialystok, E., Craik, F. I. M., \& Ryan, J. (2006). Executive control in a modified anti-saccade task: Effects of aging and bilingualism. Journal of Experimental Psychology: Learning, Memory, and Cognition, 32, 1341-1354.

Bialystok, E., Majumder, S., \& Martin, M. M. (2003). Developing phonological awareness: Is there a bilingual advantage? Applied Psycholinguistics, 24, 27-44.

Bialystok, E., \& Senman, L. (2004). Executive processes in appearance-reality tasks: The role of inhibition of attention and symbolic representation. Child Development, 75 (2), $562-579$.

Bokat, C. E., \& Goldberg, T. E. (2003). Letter and category fluency in schizophrenic patients: A meta-analysis. Schizophrenia Research, 64, 73-78.

Bolla, K. I., Lindgren, K. N., Bonaccorsy, C., \& Bleecker, M. L. (1990). Predictors of verbal fluency (FAS) in healthy elderly. Journal of Clinical Psychology, 46, 623-628. 
Borkowski, J., Benton, A., \& Spreen, O. (1967). Word fluency and brain damage. Neuropsychologia, 5, 135-140.

Butters, N., Granholm, E., Salmon, D., Grant, I., \& Wolfe, J. (1987). Episodic and semantic memory: A comparison of amnesic and demented patients. Journal of Clinical and Experimental Neuropsychology, 9, 479-497.

Crossley, M., D’Arcy, C., \& Rawson, N. S. B. (1997). Letter and category fluency in community-dwelling Canadian seniors: A comparison of normal participants to those with dementia of the Alzheimer or vascular type. Journal of Clinical and Experimental Neuropsychology, 19, 52-62.

Darcy, N. T. (1953). A review of the literature on the effects of bilingualism upon the measurement of intelligence. Journal of Genetic Psychology, 82, 21-57.

Estes, W. K. (1974). Learning theory and intelligence. American Psychologist, 29, 740-749.

Francis, W. S. (1999). Cognitive integration of language and memory in bilinguals: Semantic representation. Psychological Bulletin, 125, 193-222.

Frith, U. (1986). A developmental framework for developmental dyslexia. Annals of Dyslexia, 36, 69-81.

Gabrieli, J. D. E., Singh, J., Stebbins, G. T., \& Goetz, C. G. (1996). Reduced working memory span in Parkinson's disease: Evidence for the role of a frontostriatal system in working and strategic memory. Neuropsychology, 10 (3), 322-332.

Gollan, T. H., \& Acenas, L. A. (2004). What is TOT? Cognate and translation effect on tip-of-the-tongue states in Spanish-English and Tagalog-English bilinguals. Journal of Experimental Psychology: Learning, Memory and Cognition, 30, 246-269.

Gollan, T. H., Montoya, R. I., Fennema-Notestine, C., \& Morris, S. K. (2005). Bilingualism affects picture naming but not picture classification. Memory \& Cognition, 33 (7), 12201234.

Gollan, T. H., Montoya, R. I., \& Werner, G. A. (2002). Semantic and letter fluency in Spanish-English bilinguals. Neuropsychology, 16 (4), 562-576.

Grosjean, F. (1992). Another view of bilingualism. In R. Harris (ed.), Cognitive processing in bilinguals, pp. 51-62. New York: Elsevier.

Gourovitch, M. L., Kirkby, B. S., Goldberg, T. E., Weinberger, D. R., Gold, J. M., Esposito, G., Van Horn, J. D., \& Berman, K. F. (2000). Neuropsychology, 14, 353-360.

Hamers, J. F., \& Blanc, M. H. (2000). Bilinguality and bilingualism. Cambridge: Cambridge University Press.

Hurks, P. P. M., Hendriksen, J. G. M., Vles, J. S. H., Kalff, A. C., Feron, F. J. M., Kroes, M., Van Zeben, T. M. C. B., Steyaert, J., \& Jolles, J. (2004). Verbal fluency over time as a measure of automatic and controlled processing in children with ADHD. Brain \& Cognition, 55, 535544.

Iran Country Review (2003). Country watch incorporated. Houston, TX.

Izadi, M. R. (1992). The Kurds: A concise handbook. Washington, DC: Taylor \& Francis.

Joyce, E. M., Collinson, S. L., \& Crichton, P. (1996). Verbal fluency in schizophrenia: Relationship with executive function, semantic memory and clinical alogia. Psychological Medicine, 26 (1), 39-49.
Jurado, M. A., Mataro, M., Verger, K., Bartumeus, E., \& Junque, C. (2000). Phonemic and semantic fluencies in traumatic brain injury patients with focal frontal lesions. Brain Injury, 14, 789-795.

Kormi-Nouri, R., Moniri, S., \& Nilsson, L-G. (2003). Episodic and semantic memory in bilingual and monolingual children. Scandinavian Journal of Psychology, 44, 4754.

Kormi-Nouri, R., Shojaei, R., Moniri, S., Gholami, A., Moradi, A., Akbari-Zardkhaneh, S., \& Nilsson, L-G. (2008). The effect of childhood bilingualism on episodic and semantic memory tasks. Scandinavian Journal of Psychology, 49, 93-109.

Luo, L., Luk, G., \& Bialystok, E. (2010). Effect of language proficiency and executive control on verbal fluency performance in bilinguals. Cognition, 114, 29-41.

Mägiste, E. (1979). The competing language systems of the multilingual: A developmental study of decoding and encoding processes. Journal of Verbal Learning and Verbal Behaviour, 18, 79-89.

Marczinski, C. A., \& Kertesz, A. (2006). Category and letter fluency in semantic dementia, primary progressive aphasia, and Alzheimer's disease. Brian and Language, 97, 258265.

Martin-Rhee, M. M., \& Bialystok, E. (2008). The development of two types of inhibitory control in monolingual and bilingual children. Bilingualism: Language and Cognition, 11 (1), 81-93.

Melinder, M. R., Barch, D. M., Heydebrand, G., \& Csernansky, J. G. (2005). Easier task can have better discriminating power: The case of verbal fluency. Journal of Abnormal Psychology, 114 (3), 385-391.

Moniri, S. (2006). Bilingual memory: A lifespan approach. Ph.D. dissertation, University of Stockholm.

Nilipour, R. (1988). Bilingual aphasia in Iran: A preliminary report. Journal of Neurolinguistic, 3, 185-232.

Nilsson, L-G. (1973). Category norms for verbal material (Report 135). Uppsala: University of Uppsala.

Oren, D. L. (1981). Cognitive advantages of bilingual children related to labeling ability. Journal of Educational Research, 74 (3), 163-169.

Portocarrero, J. S., Burright, R. G., \& Donovick, P. J. (2007). Vocabulary and verbal fluency of bilingual and monolingual college students. Archives of Clinical Neuropsychology, 22, 415-422.

Rosen, W. G. (1980). Verbal fluency in aging and dementia. Journal of Clinical Neuropsychology, 2, 135-146.

Rosselli, M., Ardila, A., Araujo, K., Weekes, V. A., Caracciolo, V., Padilla, M. O., \& Ostrosky-Solis, F. (2000). Verbal fluency and repetition skills in healthy older SpanishEnglish bilinguals. Applied Neuropsychology, 7, 17-24.

Rosselli, M., Ardila, A., Salvatierra, J., Marquez, M., Matos, L., \& Weekes, V. A. (2002). A cross-linguistic comparison of verbal fluency tests. International Journal of Neuroscience, $112,759-776$.

Rosser, A., \& Hodges, J. R. (1994). Initial letter and semantic category fluency in Alzheimer's disease, Huntington's disease and progressive supranuclear palsy. Journal of Neurology, Neurosurgery, and Psychiatry, 57 (11), 13891394. 
Sauzéon, H., Lestage, P., Raboutet, C., N'Kaoua, B., \& Claverie, B. (2004). Verbal fluency output in children aged 716 as a function of the production criterion: Qualitative analysis of clustering, switching process, and semantic network exploitation. Brain and Language, 89, 192202.

Strauss, E., Sherman, E. M. S., \& Spreen, O. (2006). A compendium of neuropschological tests. Oxford: Oxford University Press.
Tucha, O., Smely, C., \& Lange, K. W. (1999). Verbal and figural fluency in patients with mass lesion of the left or right frontal lobes. Journal of Clinical and Experimental Neuropsychology, 21, 229-236.

Weiss, E. M., Ragland, J. D., Brensinger, C. M., Bilker, W. B., Deisenhammer, E. A., \& Delazer, M. (2006). Sex differences in clustering and switching in verbal fluency tasks. Journal of the International Neuropsychological Society, 12, 502-509. 